\title{
Metabolic effects of growth hormone treatment: an early predictor of growth response?
}

\author{
J W Gregory, S A Greene, R T Jung, C M Scrimgeour, M J Rennie
}

\begin{abstract}
Fourteen children receiving one year of recombinant human growth hormone (rhGH) treatment underwent measurement of serial changes in body composition (measured by skinfold thickness, bioelectrical impedance, and $\mathrm{H}_{2}{ }^{18} \mathrm{O}$ dilution), resting energy expenditure (REE, estimated by ventilated hood indirect calorimetry), and total free living daily energy expenditure (TEE, measured by the doubly labelled water technique). Mean height velocity increased from 4.9 to $8.6 \mathrm{~cm} /$ year after six months of treatment. Fat free mass (FFM) increased more during the first six weeks $(24.4 \mathrm{~g} /$ day) than from six to 26 weeks of treatment $(6.8 \mathrm{~g} /$ day $)$; fat mass decreased by $7.2 \mathrm{~g} /$ day and $1.1 \mathrm{~g} /$ day respectively. The six week increase in REE (kJ/day) was maintained after six months of treatment, though expressed per kilogram FFM (kJ/ kgFFM/day), returned to pretreatment values by three months. Height velocity increases at six months correlated with six week changes in fat mass measured by skinfold thickness and REE, though use of this relationship to predict growth response in individuals is limited by the wide $95 \%$ prediction intervals. No significant changes in growth, body composition, or energy expenditure were observed between six and 12 months of treatment, in either patients who had initially responded well to treatment or those who were poor initial responders to treatment and who had their dose of rhGH doubled after six months.
\end{abstract}

\section{(Arch Dis Child 1993;68:205-9)}

The availability of recombinant human growth hormone (rhGH) has dramatically increased its use in the treatment of short stature, although it is an expensive treatment requiring daily subcutaneous injections. It is also difficult to predict the clinical response to treatment early in the course of treatment. ${ }^{1-7}$ Height velocity changes can, at best, be measured clinically only after four to six months of treatment. Response to treatment in growth hormone deficient children appears to depend partly on the pretreatment variables of age, height, height velocity, skinfold thickness, and growth hormone secretion. ${ }^{8}$ In short normal children, greater increases in height velocity were observed in those receiving larger doses of growth hormone. ${ }^{9}$ Despite this, precise prediction of growth response to treatment in individual children is difficult; pretreatment and early increases in insulin-like growth factor-1 concentrations in response to growth hormone have not been of prognostic value, ${ }^{45}$ though increases in concentration of serum procollagen propeptide after three months of treatment correlate with height velocity changes after one year of treatment $(r=0.699, p<0.001) .{ }^{10}$

Growth hormone has several metabolic actions, including protein synthesis which is necessary for growth. The early increase in nitrogen balance with rhGH treatment does not predict the subsequent growth response to prolonged treatment. ${ }^{2}$ We have previously investigated other measures of the metabolic effect of rhGH and have described a significant increase in fat free mass (FFM) and energy expenditure in a heterogeneous group of patients receiving six weeks of rhGH treatment. In those children the increase in protein synthesis required for the observed increase in FFM to occur was estimated to account for only $7 \%$ of the observed increase in resting energy expenditure (REE). ${ }^{11}$ Growth hormone treatment must therefore cause increased energy expenditure in other ways, some of which may be the resultant processes necessary for growth. The existence of such processes might explain the poor predictive value of nitrogen retention in determining the growth response to rhGH.

We hypothesised therefore that early changes in REE and total free living energy expenditure (TEE) in response to rhGH treatment (that may be only partially indicative of the anabolic effect of $\mathrm{rhGH}$ ) may nevertheless predict the long term effects of rhGH on growth. We therefore carried out studies to investigate the changes in body composition and energy expenditure during one year of rhGH treatment. We also assessed the value of the observed early changes in these variables in predicting the long term growth response to continuous rhGH treatment. We report the findings here.

\section{Subjects and methods}

Ethical approval for the study was obtained from the committee on medical ethics of Tayside Health Board. Fifteen patients were recruited from the children's endocrine clinic as previously reported. ${ }^{11}$ This paper reports the long term results from 14 of these patients (eight boys and six girls, mean (range) age 9.9 $(7 \cdot 4-13 \cdot 7)$ years, pretreatment height SD score $-2 \cdot 2(-4 \cdot 6$ to $+1 \cdot 1)$ and height velocity $4 \cdot 9$ $(3 \cdot 1-8 \cdot 3) \mathrm{cm} /$ year) as one patient with normal variant short stature dropped out of the study after six weeks. Nine patients had growth hormone insufficiency (growth hormone $<10 \mu \mathrm{g} / \mathrm{l}$ in response to a standard insulin stress test, ${ }^{12}$ of

Department of Chil Framlington Place, Newcastle upon Tyne, NE2 4HH.

Accepted 25 September 1992 
whom two had responses less than $3.5 \mu \mathrm{g} / \mathrm{l}$; five had a response to values greater than $10 \mu \mathrm{g} / 1$; three of these had normal variant short stature. Patients were treated with daily subcutaneous injections of $2 \mathrm{IU}$ of rhGH (Norditropin, Novo Nordisk). This resulted in a mean (SE) dose of $15 \cdot 3(0 \cdot 8) \mathrm{U} / \mathrm{m}^{2} /$ week or $0.58(0 \cdot 04) \mathrm{U} / \mathrm{kg} /$ week.

Table 1 Effects of growth hormone treatment on body composition and energy expenditure. Results are mean $(S E)$

\begin{tabular}{|c|c|c|c|c|}
\hline & \multicolumn{4}{|c|}{ Weeks of treatment } \\
\hline & 0 & 6 & 12 & 26 \\
\hline 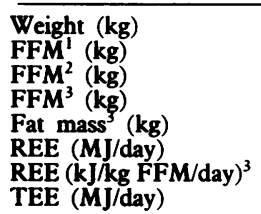 & $\begin{array}{c}25 \cdot 2(2 \cdot 2) \\
19 \cdot 6(1 \cdot 6) \\
19 \cdot 5(1 \cdot 4) \\
19 \cdot 3(1 \cdot 4) \\
5 \cdot 9(1 \cdot 0) \\
4 \cdot 1(0 \cdot 1) \\
215(10) \\
6 \cdot 8(0 \cdot 4)\end{array}$ & $\begin{array}{c}26 \cdot 1(2 \cdot 3) \\
20 \cdot 7(1.6) \\
21 \cdot 5(1.6) \\
20 \cdot 7(1 \cdot 6) \\
5 \cdot 4(1 \cdot 0) \\
4 \cdot 5(0 \cdot 2) \\
226(12) \\
7 \cdot 3(0 \cdot 4)\end{array}$ & $\begin{array}{c}26 \cdot 1(2 \cdot 2) \\
21 \cdot 0(1 \cdot 6) \\
21 \cdot 5(1.4) \\
20 \cdot 8(1 \cdot 5) \\
5 \cdot 3(0 \cdot 9) \\
4 \cdot 4(0 \cdot 1) \\
219(11) \\
6 \cdot 8(0 \cdot 3)\end{array}$ & $\begin{array}{c}26 \cdot 9(2 \cdot 4) \\
22 \cdot 0(1 \cdot 7) \\
23 \cdot 0(1 \cdot 6) \\
21 \cdot 7(1 \cdot 7) \\
5 \cdot 2(0 \cdot 9) \\
4 \cdot 4(0 \cdot 2) \\
213(10) \\
7 \cdot 4(0 \cdot 4)\end{array}$ \\
\hline
\end{tabular}

=Determined by skinfold thicknesses; 2 =determined by bioelectrical impedance; and $3=$ determined by $\mathrm{H}_{2}{ }^{18} \mathrm{O}$ dilution.

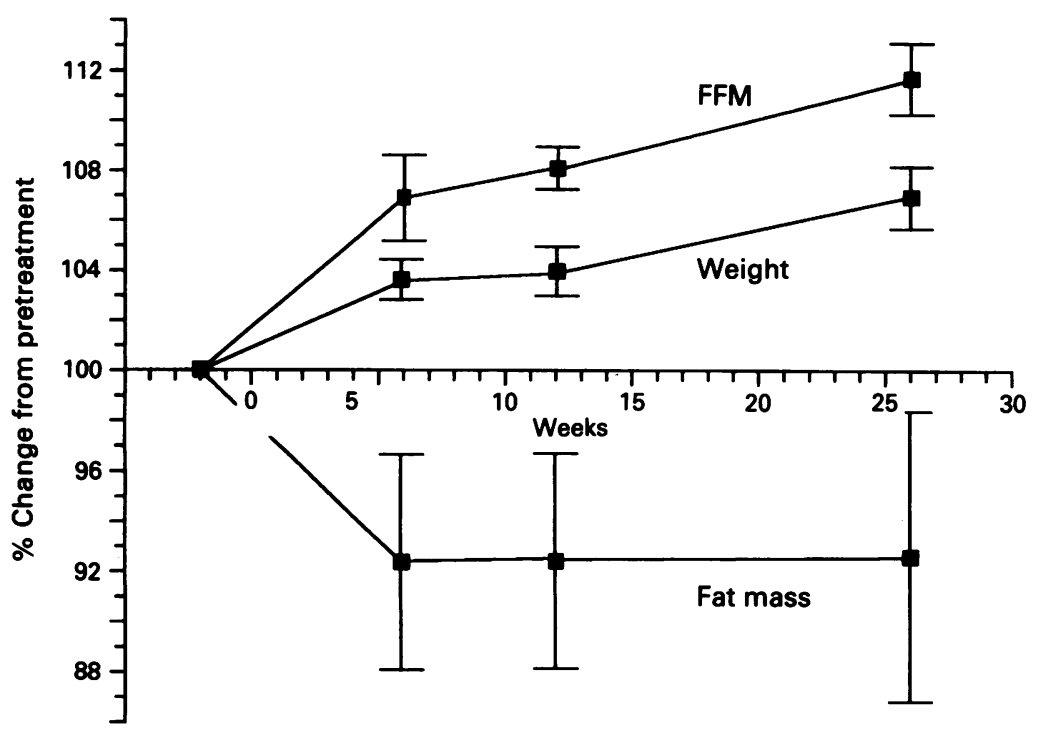

Figure 1 Mean (SE) changes in body composition with six months of rhGH treatment.

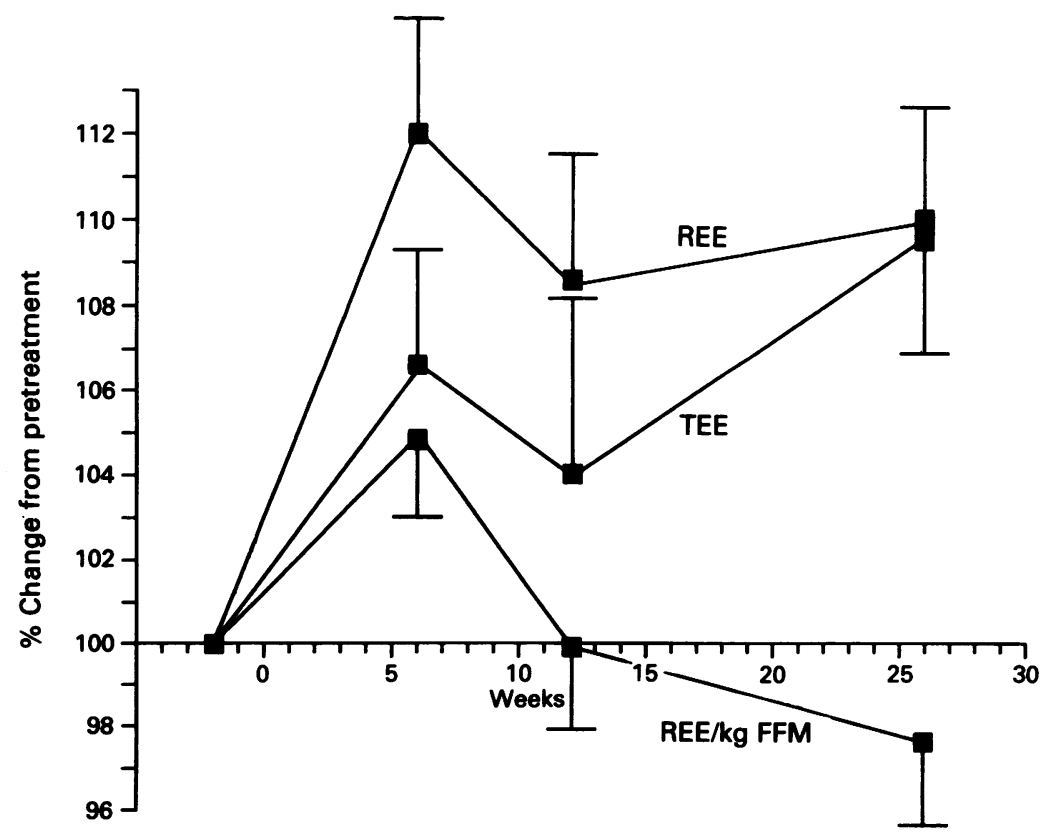

Figure 2 Mean (SE) changes in energy expenditure with six months of rhGH treatment.
After 26 weeks of treatment, the dose of rhGH was increased to 4 IU daily in patients who had not doubled their pretreatment growth velocity, though one patient in this group was removed from the study after nine months because of unwillingness to continue treatment due to his poor response.

Anthropometric, body composition, and energy expenditure measurements were made before and 6, 12, 26, 39, and 52 weeks after starting rhGH treatment. In those patients who doubled their dose of rhGH after 26 weeks, an extra measurement of body composition and energy expenditure was made six weeks later. Anthropometric and body composition measurements (by $\mathrm{H}_{2}{ }^{18} \mathrm{O}$ dilution, bioelectrical impedance, and skinfold thicknesses) were made as described previously. ${ }^{11} 13$

Both REE and TEE were measured. REE was estimated in a fasting state and in a thermoneutral environment by ventilated hood indirect calorimetry. ${ }^{14}$ REE was calculated from measurements of oxygen consumption and carbon dioxide production using Weir's equation. ${ }^{15}$ TEE was measured by the doubly labelled water method, ${ }^{16}{ }^{17}$ using the protocol described previously, ${ }^{11}$ but with a minor modification to the calculation used to estimate energy expenditure. ${ }^{18}$ TEE calculated by this method is a mean value for energy expenditure over a two week period.

Before and after treatment results were analysed statistically using a Wilcoxon rank test for paired data and the Spearman rank order correlation coefficient test. Significance was assigned at the level of $5 \%$; $95 \%$ confidence intervals $(\mathrm{CI})$ were calculated where appropriate.

\section{Results}

EFFECT OF SIX MONTHS OF RHGH TREATMENT

Mean (SE) height velocity increased to $8 \cdot 3(0 \cdot 6)$ $\mathrm{cm} /$ year after 12 weeks of rhGH treatment and was $8.6(0.6) \mathrm{cm} /$ year after six months. Similar changes in body composition were observed using all three methods (table 1). Mean weight and FFM having increased significantly $(\mathrm{p}<0.005$ and $\mathrm{p}<0.001$ respectively) after six weeks of treatment, increased more slowly thereafter (table 1 and fig 1). Fat mass having decreased after six weeks of treatment showed no further consistent response among individual patients.

Mean whole body REE was unchanged after the initial significant increase $(p<0.005)$ at six weeks. When expressed per $\mathrm{kg}$ of FFM (measured by isotope dilution), REE returned to pretreatment values by 12 weeks (table 1 and fig 2). TEE having increased markedly at six weeks $(p<0.05)$ showed much variability in individual responses thereafter. Despite this, the difference between mean REE and mean TEE remained unaltered after the six months of the study.

Height velocity before rhGH treatment was correlated with the subsequent increase in height velocity $(r=-0.60, p<0.05)$ but not with any of the changes in body composition or energy expenditure during treatment. The increase in height velocity after six months of 
Table 2 Correlations between changes in body composition and energy expenditure at six weeks with changes in growth velocity at six months

\begin{tabular}{lrl}
\hline & $r$ & $p$ \\
\hline REE (kJ/day) & 0.82 & $<0.005$ \\
REE (kJ/kg FFM/day) & 0.77 & $<0.01$ \\
Total energy expenditure & 0.56 & $<0.05$ \\
Fat mass (H. ${ }_{2}^{18}$ O dilution) & -0.57 & $<0.05$ \\
Fat mass (skinfolds) & -0.90 & 0.001 \\
FFM (H ${ }^{18}$ O dilution) & 0.11 & NS \\
\hline
\end{tabular}

${ }^{*}$ FFM measured by isotope dilution.

rhGH treatment correlated (table 2) with six week changes in REE (expressed both as $\mathrm{kJ} /$ day and $\mathrm{kJ} / \mathrm{kg} \mathrm{FFM/day)} \mathrm{and} \mathrm{with} \mathrm{six} \mathrm{week} \mathrm{changes}$ in TEE and fat mass measured both by skinfold thicknesses (fig 3) and by isotope dilution. There was no association between the dose of rhGH (expressed either as $\mathrm{U} / \mathrm{kg} /$ week or $\mathrm{U} / \mathrm{m}^{2}$ / week) and six month height velocity $(r=0.33$, $p=0.23$ and $r=0.34, p=0.22$ respectively) or any of the changes in body composition or energy expenditure. Increases in FFM observed after six weeks did not correlate with six month changes in height velocity (table 2 ). The relationship between the six month increase in height velocity ( $y)$ and six week change in fat mass measured by skinfold thicknesses ( $x$ ) is represented by the regression equation:

$$
y=-2 \cdot 934 x+3.09 \text { (fig 3). }
$$

The $95 \% \mathrm{CI}$ for the slope of the regression line is $-4 \cdot 432$ to $-1 \cdot 428$. A mean change in fat mass of $-0.26 \mathrm{~kg}$ during the first six weeks of rhGH treatment would be associated with an increase in height velocity of $3.85 \mathrm{~cm} /$ year $(95 \%$ CI 2.83 to $4.87 \mathrm{~cm} /$ year) after six months of treatment. However, the $95 \%$ prediction interval for height velocity change in an individual with the same

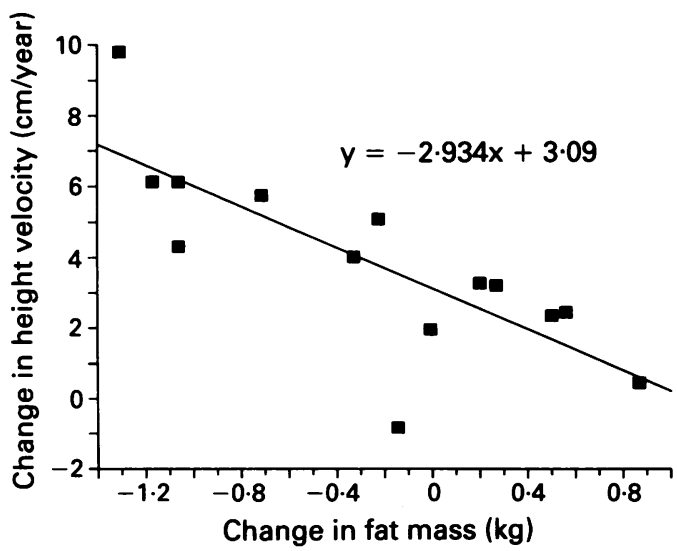

Figure 3 Relationship between changes in fat mass (six weeks) and height velocity (six months). initial change in fat mass would be -0.11 to $7 \cdot 81 \mathrm{~cm} /$ year.

\section{EFFECT OF ONE YEAR OF RHGH TREATMENT}

After six months of rhGH treatment, six patients who had doubled their pretreatment growth velocity and one patient whose growth velocity remained satisfactory at $10.2 \mathrm{~cm} /$ year (though this did not represent a doubling of his growth velocity in the immediate six months before starting treatment) remained on 2 IU rhGH daily (group 1). Seven patients increased their rhGH dose to 4 IU daily because of a poor response to treatment (group 2).

\section{(A) Patients on 2 IU rhGH daily (group 1)}

In this group, height velocity progressively decreased between six and 12 months (fig 4). A steady increase in FFM and fat mass was observed (fig 4). The one year height velocity increase against pretreatment values, correlated with the six week increase in FFM $(r=0.82$, $\mathrm{p}<0.05)$ and $\operatorname{REE}(\mathrm{r}=0.88, \mathrm{p}<0.05)$ though the association with the six week changes in fat mass and dose of rhGH corrected for body
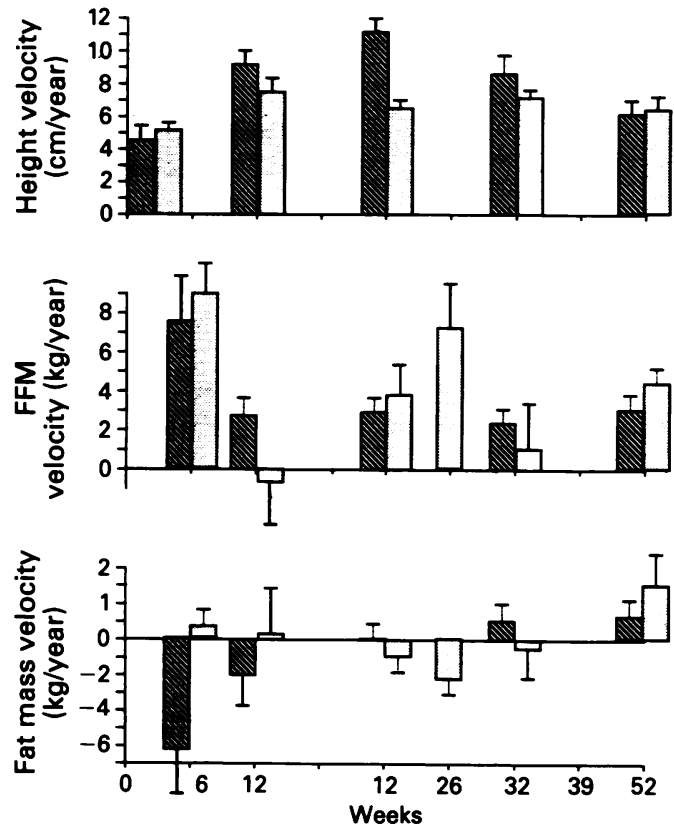

$\mathbb{N}=2$ IU rhGH daily

$\square=2 I U$ daily, increased to 4 IU daily after six months

Figure 4 Mean (SE) auxological changes in each treatment group.

Table 3 Comparison of energy expenditure between those cases who remained on 2 IU rhGH treatment for one year (group 1 ) and those who increased to 4 IU after six months (group 2) because of an inadequate growth response. Results are mean (SE)

\begin{tabular}{|c|c|c|c|c|c|c|}
\hline \multirow[t]{2}{*}{ Length of treatment } & \multicolumn{2}{|l|}{$\begin{array}{l}R E E \\
(k \mathcal{k} / d a y)\end{array}$} & \multicolumn{2}{|c|}{$\begin{array}{l}R E E \\
(k \mathcal{k} / \mathrm{kg} \text { FFM/day) }\end{array}$} & \multicolumn{2}{|l|}{$\begin{array}{l}T E E \\
(k \mathcal{k} / \text { day })\end{array}$} \\
\hline & Group 1 & Group 2 & Group 1 & Group 2 & Group 1 & Group 2 \\
\hline $\begin{array}{l}\text { Pretreatment } \\
\text { After treatment (weeks): }\end{array}$ & 3800 (123) & $4375(210)$ & $220(8)$ & $202(18)$ & $6450(414)$ & $8029(980)$ \\
\hline $\begin{array}{l}6 \\
12 \\
26 \\
32\end{array}$ & $\begin{array}{l}4474(267) \\
4278(156) \\
4254(200)\end{array}$ & $\begin{array}{l}4662(184) \\
4522(173) \\
4662(229) \\
4960(314)\end{array}$ & $\begin{array}{l}242(8) \\
229(9) \\
218(8) \\
-\quad\end{array}$ & $\begin{array}{l}202(19) \\
204(18) \\
208(19) \\
210(14)\end{array}$ & $\begin{array}{l}6956(558) \\
6407(438) \\
7245(461) \\
-\end{array}$ & $\begin{array}{l}8274(877) \\
7771(711) \\
7577(590) \\
7786(526)\end{array}$ \\
\hline 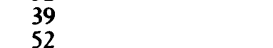 & $4333(188)$ & 4728 (226) & $217(10)$ & 201 (15) & $7608(552)$ & 8400 (537) \\
\hline 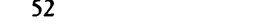 & $4344(230)$ & $5106(404)$ & $209(8)$ & $206(14)$ & $8083(816)$ & $8562(323)$ \\
\hline
\end{tabular}


weight did not reach significance with such small numbers (both $r=-0.71, p=0.08$ ). REE per $\mathrm{kg}$ FFM remained at pretreatment values and there was a steady increase in TEE (table 3).

\section{(B) Patients on 4 IU rhGH daily (group 2)}

A minimal and transient increase in height velocity was observed during the first three months on the increased dose of rhGH (fig 4). A transient increase in the daily incremental increase of FFM similar to that seen in this group during the first six months of treatment was also observed (fig 4). Unlike the trend in this group during the first six months, a transient decrease in FM was observed on the bigger dose of rhGH (fig 4). No clear trends in energy expenditure were seen in this group (table 3). As in the group of patients who remained on $2 \mathrm{IU}$ of rhGH, numbers of patients for analysis are small. No statistically significant correlations were demonstrated between the increase in height velocity after six months of rhGH (4 IU daily) and changes in body composition or energy expenditure after six weeks on the increased dose, though changes in fat mass alone nearly reached significance $(r=0 \cdot 77$, $\mathrm{p}=0.08$ ).

\section{Discussion}

Growth hormone treatment is known to increase nitrogen retention within 48 hours, an effect which reaches a maximum within two weeks of starting treatment. Thereafter, the extent of the effect appears to become attenuated and to return towards pretreatment values. ${ }^{19}$ We have observed, albeit over a longer period of time, a similar attenuation of the effect of rhGH on the serial changes in body composition and resting energy expenditure per kg FFM. FFM increased at a rate of $24.4 \mathrm{~g}$ /day during the first six weeks of treatment but at only $6.8 \mathrm{~g}$ /day thereafter. After an initial increase in REE per kg FFM, values returned to pretreatment levels by 12 weeks. This finding explains why some investigators could not show a significant effect of rhGH on the metabolic activity of the FFM when no measurements were made until after six months of treatment. ${ }^{20}$ The latter study described the responses only of patients without evidence of growth hormone deficiency. We observed no significant differences in response between patients with growth hormone deficiency and those with normal pretreatment responses to insulin stress testing. It was also reported that REE per kg FFM correlated negatively with pretreatment height, ${ }^{20}$ but in the heterogeneous group of patients studied here, we found no evidence for this.

The significant associations between the changes in the variables measured after six weeks and the growth response after six months of treatment (table 2) suggest that, in our heterogeneous group of patients, measurement of substantial early changes in fat mass or energy expenditure may be of value in predicting those patients likely to respond to rhGH treatment in a wide variety of growth disorders. In keeping with the findings of other studies, ${ }^{21}$ the equations produced (fig 3) have wide $95 \%$ prediction intervals, which limits their value in predicting precise increases in individual height velocities. The wide prediction intervals may relate both to the small numbers of patients studied and the imprecision in height velocity measurements made over intervals as short as six months. ${ }^{22}$ The lack of significant association between the individual doses of rhGH (corrected for body size) and any of those six week changes in body composition and energy expenditure that were predictive of subsequent height velocity changes suggests that such relationships may not be dependent on the dose given. Indeed, the most significant association between any change observed at six weeks and the dose of rhGH was that with the increment in FFM $(\mathrm{r}=-0.49, \mathrm{p}=0.08)$. Remarkably, this was the only change in body composition observed at six weeks which was not correlated with longer term changes in height velocity (table 2 ).

The significant correlation between the change in REE after six weeks and the increment in height velocity after six months of treatment suggests that if the increase in REE is a measure of the metabolic response to treatment, then this is ultimately directly related to growth response even when the latter can only be measured after longer time periods. The less statistically significant association with the six week changes in TEE probably reflects the confounding effect of physical activity which contributes to this measure of energy expenditure and which is unaffected by rhGH treatment (as demonstrated by the constant difference between mean TEE and REE after six months of treatment).

It is of note that the correlation between six week changes in fat mass and six month increases in height velocity is greater when fat mass derived from skinfold thickness rather than isotope dilution is used. This is fortuitous as the skinfold technique could be used routinely in clinical practice; it may reflect the fact that skinfold thickness changes not only reflect decreases in body fat but may also fall if underlying bone and muscle circumference increases. In addition, body fat changes measured by skinfold thicknesses may be more accurately determined as they are less affected by small increases in oedema than those measured by isotope dilution. Furthermore, it is known that site specific changes in adipose distribution during growth hormone treatment are due in part to growth hormone mediated changes in the insulin responsiveness of adipose tissue, ${ }^{23}$ resulting in a redistribution of adipose tissue from an abdominal (android) to a more gluteal (gynoid) distribution. In the same study, ${ }^{23}$ it was also reported that the adipose tissue sensitivity to insulin mediated antilipolysis in vitro is correlated to growth velocity. These findings suggest that compared with whole body fat mass measurement by isotope dilution, skinfold thickness measurements may be a more sensitive measure of the metabolic response to $\mathrm{rhGH}$, measuring both loss of fat mass to provide fuel energy and also redistribution of fat as part of the alteration of body composition. 
The finding that, six week increases in FFM do not correlate with six month increases in height velocity in the study group as a whole, is in keeping with previous studies reporting the lack of correlation between early estimates of nitrogen retention and longer term growth. ${ }^{27}$ Though increments in FFM might be expected to be a measure of the anabolic effect of $\mathrm{rhGH}$, the calorigenic effect of $\mathrm{rhGH}$ treatment is greater than that produced by the presumed increase in protein synthesis. ${ }^{11}$ We hypothesise that other unknown effects of rhGH, for example, factors affecting sodium pump activity and cardiovascular energy expenditure may be related to growth response.

In conclusion, we have demonstrated that the effects of rhGH treatment on REE per kg FFM and on the extent of changes in body composition decreased after six weeks of treatment. Nevertheless, six week changes in fat mass, REE, and TEE are significantly correlated with six month increases in height velocity. In clinical practice, the $95 \%$ prediction intervals of the equation (fig 3) are wide and limit the precision of the predicted increase in height velocity for individual patients. The data suggest that further, larger studies are indicated to assess the value of measurements of the early changes in body composition in the prediction of the long term growth response to rhGH treatment.

This work was supported by grants from the Biomedical Research Council of The Scottish Home and Health Department, Novo-Nordisk A/S, Birthright, The Wellcome Trust, The University of Dundee, and The European Social Fund. We are grateful to Mr M Rollo for assistance with some of the isotopic analysis.

1 Wales JKH, Milner RDG. Changes in leg length and height during treatment with somatropin. Arch Dis Child 1989;64: during treat 12 .

2 Clayton BE, Tanner JM, Vince FP. Diagnostic and prognostic value of short-term metabolic response to human growth hormone in short stature. Arch Dis Child 1971;46:405-13.

3 Gertner JM, Genel M, Gianfredi SP, et al. Prospective clinical trial of human growth hormone in short children without growth hormone deficiency. F Pediatr 1984;104:172-6.

4 Plotnick LP, van Meter QL, Kowarski AA. Human growth hormone treatment of children with growth failure and normal growth hormone levels by immunoassay: lack of correlation with somatomedin generation. Pediatrics 1983; 71:324-7.

5 Grunt JA, Howard CP, Daughaday WH. Comparison of growth and somatomedin $\mathrm{C}$ responses following growth hormone treatment in children with small-for-date short stature, significant idiopathic short stature and hypopituitarism. Acta Endocrinol (Copenh) 1984;106:168-74.

6 Wright JC, Brasel JA, Aceto T, et al. Studies with human growth hormone $(\mathrm{HGH})$. An attempt to correlate metabolic response during short-term administration with linear growth during prolonged therapy. Am 7 Med 1965;38: growth $499-516$.

7 Dahms WT, Owens RP, Kalhan SC, Kerr DS, Danish RK. Urea synthesis, nitrogen balance, and glucose turnover in growth-hormone-deficient children before and after grow

8 Milner RDG, Russell-Fraser T, Brook CGD, et al. Experience with human growth horone in Great Britain: the report of the MRC working party. Clin Endocrinol (Oxf) 1979;11: 15-38.

9 Hindmarsh PC, Brook CGD. Effect of growth hormone on short normal children. BMF 1987;295:573-7.

10 Trivedi P, Hindmarsh P, Risteli J, Risteli L, Mowat AP, Brook CGD. Growth velocity, growth hormone therapy, and serum concentrations of the amino-terminal propeptide of type III procollagen. 7 Pediatr 1989;114:225-30

11 Gregory JW, Greene SA, Jung RT, Scrimgeour CM, Rennie MJ. Changes in body composition and energy expenditure after six weeks' growth hormone treatment. Arch Dis Child $1991 ; 66: 598-602$.

12 Hughes IA. Handbook of endocrine tests in children. Bristol: Wright, 1986:133-4

13 Gregory JW, Greene SA, Scrimgeour CM, Rennie MJ. Body water measurement in growth disorders: a comparison of bioelectrical impedance and skinfold thickness techniques with isotope dilution. Arch Dis Child 1991;66:220-2.

14 Crisp JA, Murgatroyd PR. A versatile and mobile microcomputerised system for indirect calorimetry. In: van Es AJH, ed. Human energy metabolism: physical activity and energy expenditure measurements in epidemiological and energy expenditure measurements in epidemiological research based upon direct and indirect calorimetry. Euro-Nut, The Hague: Cip-Gegevans

15 Weir JBdeV. New methods for calculating metabolic rate with special reference to protein metabolism. I Physiol (Lond) 1949;109:1-9.

16 Lifson N, Gordon GB, McClintock R. Measurement of total carbon dioxide production by means of $\mathrm{D}_{2} \mathrm{O}^{1 \mathrm{x}}$. $\mathcal{J} A p p l$ Physiol 1955;7:704-10.

17 Schoeller DA, van Santen E. Measurement of energy expenditure in humans by doubly labelled water method. If Appl Physiol 1982;53:955-9.

18 Gregory JW, Greene SA, Thompson J, Scrimgeour CM, Rennie MJ. Effects of oral testosterone undecanoate on growth, body composition, strength and energy expenditure of adolescent boys. Clin Endocrinol (Oxf) 1992;37:207-13.

19 Henneman PH, Forbes AP, Moldawer M, Dempsey EF, Carroll EL. Effects of human growth hormone in man. F Clin Invest 1960;39:1223-38.

20 Walker JM, Bond SA, Voss LD, Betts PR, Wootton SA, Jackson AA. Treatment of short normal children with growth hormone-a cautionary tale? Lancet 1990;336: growth

21 Tanner JM, Hughes PCR, Whitehouse RH. Comparative rapidity of response of height, limb muscle and limb fat to treatment with human growth hormone in patients with and without growth hormone deficiency. Acta Endocrinol (Copenh) 1977;84:681-96.

22 Voss LD, Wilkin TJ, Bailey BJR, Betts PR. The reliability of height and height velocity in the assessment of growth (the Wessex Growth Study). Arch Dis Child 1991;66:833-7.

23 Rosenbaum M, Gertner JM, Leibel RL. Effects of systemic growth hormone $(\mathrm{GH})$ administration on regional adipose tissue distribution and metabolism in GH-deficient children. F Clin Endocrinol Metab 1989;69:1274-81. 